\title{
Integrated Speed Bump Detector to notify road users using Internet of Things
}

\author{
SYAZA NADIA HAIRUDIN*1, AZLINA AHMADI JULAIHI*1 \& TAN PING PING*1 \\ ${ }^{1}$ Faculty of Computer Science and Information Technology, Universiti Malaysia Sarawak, 94300 Kota \\ Samarahan, Sarawak, Malaysia \\ *Corresponding authors: ajazlina@unimas.my; pptan@unimas.my
}

\begin{abstract}
Every year all over the world, many lives are lost due to accidents on the roads. Different factors have contributed to this tragic death, such as the poor condition of roads and bad weather such as rain. To solve this problem, an Integrated Speed Bump Detector to notify road users using the Internet of Things (IoT) has been proposed to help road users to detect speed bumps earlier by getting notified through sound from the buzzer and red light from an LED. This also increases the safety of road users during their trips and provides information if a speed bump is approaching. The ultimate goal of this project is to prevent an accident from occurring during road trips and to promote a careful attitude among road users.
\end{abstract}

Keywords: Internet of Things (IoT), speed bump detector, safety, road users

Copyright: This is an open-access article distributed under the terms of the CC-BY-NC-SA (Creative Commons Attribution-NonCommercial-ShareAlike 4.0 International License) which permits unrestricted use, distribution, and reproduction in any medium, for non-commercial purposes, provided the original work of the author(s) is properly cited.

\section{INTRODUCTION}

Technology is now part of human life and human nowadays sometimes cannot live without it. Society also has been changed with the evolution of powerful technology. Before the advent of advanced technology, the majority of people must meet face to face but with smartphones, they just have to call or message the other person. Thanks to technology, human life has been drastically upgraded and time, money, and energy can be saved for other things. Technology in cars is also more powerful now, which enables humans to travel safely to their destination in a short time. However, road hazards such as careless drivers, driving distractions and unsafe roads contribute to the increasing number of accidents. Road abnormalities such as manholes, potholes, and speed bumps also contribute towards unsafe and dangerous roads. Technological means have been utilized to prevent, eliminate, or lessen threats to life and the environment and to fulfill social needs (Sueb, 2013). The purpose of this project is to create a system to detect speed bumps and give early notification to road users so that the road users can take precautions and avoid unexpected events.

According to Patel and Gundaliya (2017), a speed bump is a raised pavement surface that provides a physical reminder for motorists to slow down while traveling over it. The role of speed bumps is to force drivers and motorcyclists to reduce their vehicle speed to avoid the occurrence of accidents. The first speed bump was implemented in Chatham, New Jersey in 1906; it was designed by Arthur Holly Compton after he noticed the speed of motorists passing Brookings Hall at Washington University in St. Louis, Missouri when he was a chancellor (ACPLM, 2019).

Many countries randomly place speed bumps on roads and they can be found near schools, playgrounds and hospitals for the safety of both drivers and pedestrians. Sometimes, a traffic sign that shows there is a bump ahead may not exist and the driving pattern is disturbed, and road users may hit the bumps at a high speed causing accidents and damage to their vehicles. A 2014 road accident report from India showed that a total of 4726 lives were lost due to crashes at speed breakers on National Highways (Patel \& Gundaliya, 2017). According to World Health Organization, approximately 1.35 million people die each year as a result of road traffic crashes (WHO, 2018). Other than driver carelessness, road abnormalities such as manholes, potholes, and speed bumps are also reasons why accidents occur. As a result, drivers, pedestrians, and motorcyclists suffer injuries not due to their own fault.

Besides, when the environment is dark, at night, or when it is raining, road users tend not to see the road clearly. Moreover, the streetlights near the speed bump may also not be bright enough, and the yellow and black line at the speed bump may become faded due to rain. Road signs alerting users to the presence of speed bumps 
may also be missing or broken. Therefore, obstacles on the road such as speed bumps may not be visible to the users; if road users drive vehicles at the maximum speed without being aware of such obstacles, serious accidents and damage to vehicles may occur. These problems can be solved by early detection of speed bumps ahead and notification of road users so they have enough time to slow down their vehicle before hitting the bump. A prototype to solve these problems has been developed which is an Integrated Speed Bump Detector to notify road users using the Internet of Things (IoT).

\section{LITERATURE REVIEW}

Three existing systems have been selected to be discussed in this paper: Development of Digital Vehicle Distance Monitoring System, Automatic Road Accident Detection using Ultrasonic Sensor and Vehicle Safety Distance Alarming System. All these systems have their own characteristic, advantages, and disadvantages.

Muhaiyiddin, Sanudin, Wahab and Johari (2019) designed a system to help the driver to estimate the distance between the car and an object, whether it is in front of or behind the car, can contribute to reducing the number of incidents. A PIC16F84A microcontroller which has been programmed using MPLAB software is used to analyze and send commands to measure the distance between the car and objects within the focused range which is between $1 \mathrm{~m}$ to $5 \mathrm{~m}$. The ultrasonic sensor will detect objects in front or behind the car and a signal will be sent to the microcontroller. After that, the analog to digital converter will receive the data to measure and convert it into the digital signal. Then, the distance between the car and the object will be displayed on the LCD.

Khalil, Nasir, Khan, Javid, Raza and Siddiqui (2018) designed a system that could detect road accidents and immediately inform the emergency department accordingly. It used an ultrasonic sensor module HCSR04 to measure the distance. Two ultrasonic sensors are placed on the front and back windscreens of the car and the distance between the ultrasonic sensors and respective bumpers is measured. These distances are named threshold distance 1 and threshold distance 2. The threshold distance is breached when an object collides with the car and the processing system is turned on immediately. Once the incidents occur, GPS will send the location of the car to the emergency department immediately through GSM.

The third system was proposed for disabled drivers who need a clear visual and/or audible alarm (Attia, Ismail and Alia (2017). The function of this system is to monitor the actual speed of the host vehicle and the actual distance between the host vehicle and the vehicle in front. Furthermore, this design system is based on general electronic discrete components without using any specific controller or digital processing unit. The speed sensor is used to sense the actual speed of the host vehicle. Meanwhile, a distance sensor is used to measure the actual distance between the host and front vehicles. In this system, the actual data state of the vehicle and the road has been collected to come up with them suitable audio-able and visual alarms for three different situations. Firstly, when the distance between the host vehicle and the front vehicle is less than a certain minimum distance limit. Secondly, when a vehicle running at a low speed and the distance between two cars is further than a certain maximum distance limit and lastly, the system will trigger the host car if the distance is perfectly suitable in distance range conditions.

\section{MATERIALS \& METHODS}

\section{Requirement Analysis}

Rapid Application Development (RAD) as shown in Figure 1 was used to develop this system. RAD is a software development process which targets to reach system completion within $60-90$ days (Walter, 1997); this was considered suitable for the proposed system as it is a small and embedded system that requires around 90 days to develop. There are four phases in the RAD methodology, as follows:

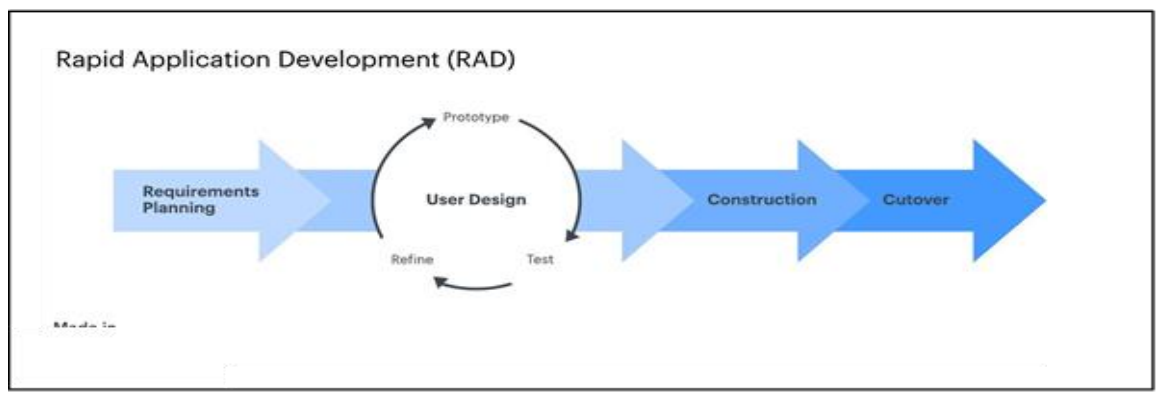

Figure 1. RAD phases (Rapid Application Development (RAD): Changing How Developers Work, 2021) 


\section{System Design}

This section details the process flow in the proposed system, as well as each functionality. In the proposed system, there are several functions providing a mechanism to alert road users about speed bumps through sounds from a buzzer and red lights from the LED. The flowchart can be viewed in Figure 2.

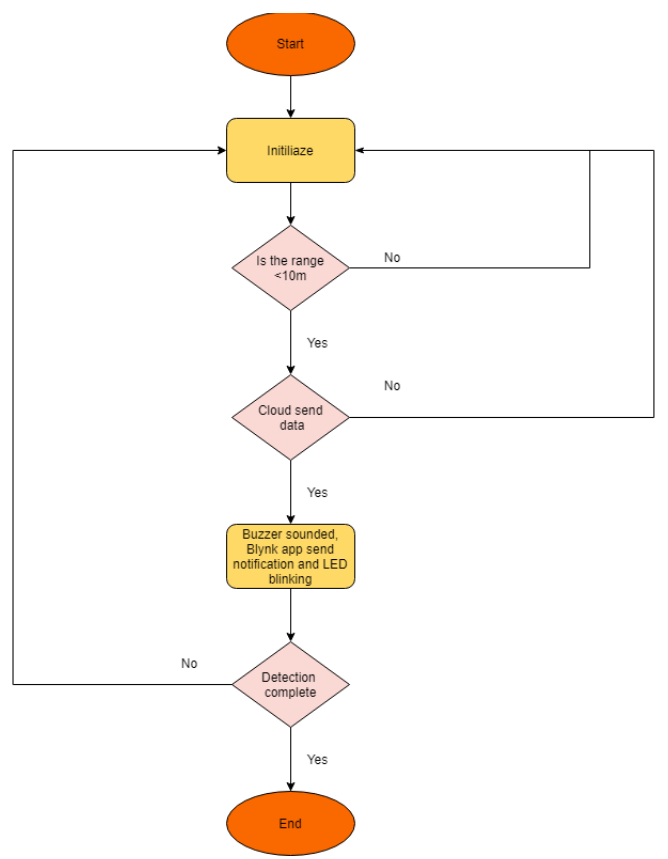

Figure 2: Process of the System Design

\section{A. Use Case Diagram}

The general overview of the system is shown in Figure 3. The user needs to turn the speed bump detector system on to use the system. The user can also receive notification alerts and view the camera to detect any incoming speed bumps. The ultrasonic sensors will trigger the buzzer which will release a sound if it detects a speed bump within a distance of less than 10m. Figure 3 shows the use case diagram for Integrated Speed Bump Detector to notify road users using Internet of Things (IoT).

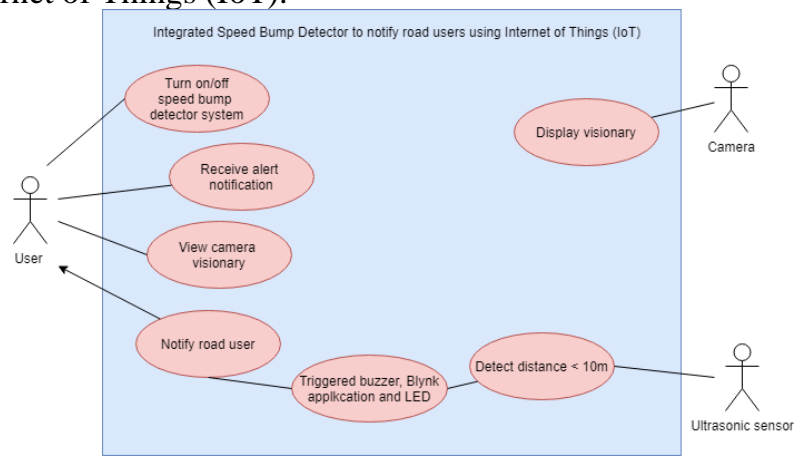

Figure 3: Use case diagram of the proposed system

\section{RESULTS}

Methods to capture the interface layouts are used to illustrate the details and structure of the prototype. The implementation of the proposed system is divided into two parts: software and hardware. Testing was performed to check whether those functions are working as predicted and meet the requirements. Several tools were used to establish the system, as listed below. 


\section{a) Arduino Nodemcu ESP32}

Arduino Nodemcu ESP32 is a successor to the ESP8266 microcontroller. It has more advanced features than the ESP8266, with more CPU cores, faster Wi-Fi speed, more GPIOs, and support for both Bluetooth 4.2 and Bluetooth low energy. Other than that, it also has interesting features such as sensitive pins which are used to wake up the ESP32 if it fell asleep. In addition, the Arduino also has a built-in half effect sensor and temperature sensor. ESP32 has 32 GPIO pins and each can be decided upon to be a UART, 12C, and SPI. This is possible due to the ESP32 chips having an advanced multiplexing feature that allows the setting of various functions on the same pin. Arduino IDE needs installation from any online resources to upload the microcontroller.

\section{b) Ultrasonic Sensor HC-SR04}

For the ultrasonic sensor HC-R04, it needs to be coded first in the Arduino IDE before it can function successfully. This ultrasonic sensor measures the distance between a car and the speed bump. Once the distance between a car and the speed bump reaches below 10m, the ultrasonic sensor will send a signal to the microcontroller, and the microcontroller will send a signal to the buzzer, red LED, and Blynk application to alert the road user on the upcoming speed bump. If the distance is more than $10 \mathrm{~m}$, the ultrasonic sensor will not trigger the alert.

\section{c) ESP32 Camera}

ESP32 Camera function needs to be coded first in the Arduino IDE before it can be functional. The camera module serves to detect the image of the speed bump and send a signal to the microcontroller accordingly. From that, the road users will get an alert signal from the buzzer, red LED, and the Blynk application.

\section{d) Arduino Mega 2560}

The Arduino Mega 2560 is a microcontroller board based on the ATmega2560. It is designed for projects that need more I/O, sketch memory, and RAM. It contains everything required to support the microcontroller such as 54 digital input/output pins (of which 14 can be used as PWM output), 16 analog input, 4 UARTs (hardware serial ports), a $16 \mathrm{MHZ}$ crystal oscillator, a USB connection, a power jack, an ICSP header, and a reset button. A larger space available to fulfil the recommended board for any 3D printers and robotics projects. The microcontroller is connected to the laptop with a USB cable to get it started. Lastly, this microcontroller is compatible with all the shields that are designed for the Arduino Duemilanove or Diecimilia. Arduino IDE needs to be installed to upload the code into the microcontroller.

\section{e) Blynk Application}

An application is used to alert the road users through the mobile phone which is the Blynk application. In this application, when the microcontroller gets a signal from the hardware component about the approaching speed bump, it will produce a sound to alert the road users.

\section{DISCUSSION}

To show how this Integrated Speed Bump Detector to Notify Road users using Internet of Things (IoT) system functions, a small model prototype was developed (Figure 4). In this proposed system, cardboard was used to make a road and a speed bump, while a toy car is used as a prototype of the actual car. Ultrasonic sensors and a camera module was placed on the front of the car. This is the simulation of the real-life scenario where the ultrasonic sensor will sense the speed bump within a distance of less than $10 \mathrm{~m}$, and the camera will display the visionary. However, in this proposed system, the threshold is $23 \mathrm{~cm}$. The notification used to notify road users via the Blynk application is shown below.

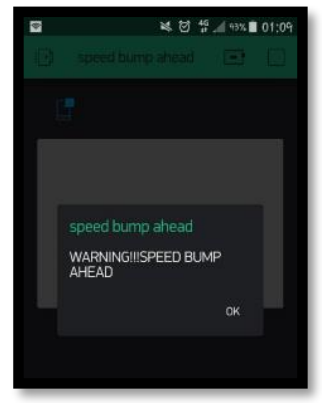

Figure 4: Notification in the Blynk application 
Trends in Undergraduate Research (2021) 4(2): c1-8

https://doi.org/10.33736/tur.2783.2021

\section{Prototype Testing}

The two types of testing that need to be performed are component testing and complete circuit testing.

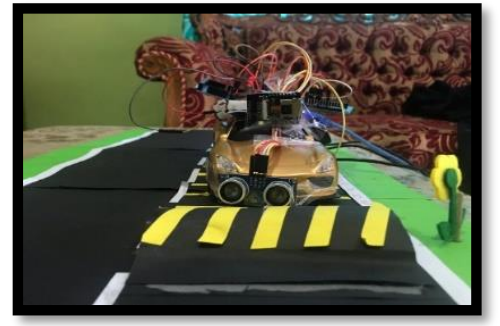

Figure 5: Ultrasonic sensor and Camera module been tested to detect the speed bump

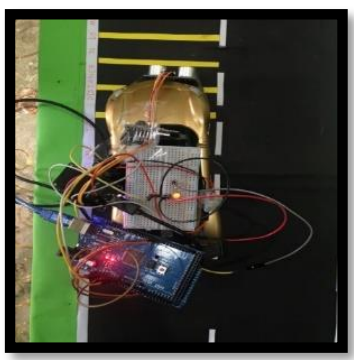

Figure 6: Ultrasonic and Camera module with red LED and a buzzer

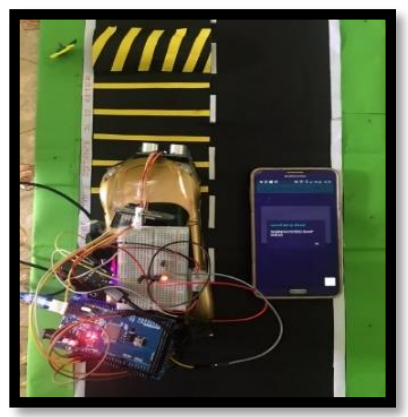

Figure 7: Complete testing of the prototype

For the ultrasonic sensor testing, the sensor was first connected to the ESP32 microcontroller. In this testing, the ultrasonic sensor acted as the input, while the output was the sound from the buzzer and red light from the LED. Once the ultrasonic sensor detected that the distance between the car and the speed bump was below 10m, a buzzer produced a sound and red light from the LED switched on to alarm the road users about the approaching speed bump.

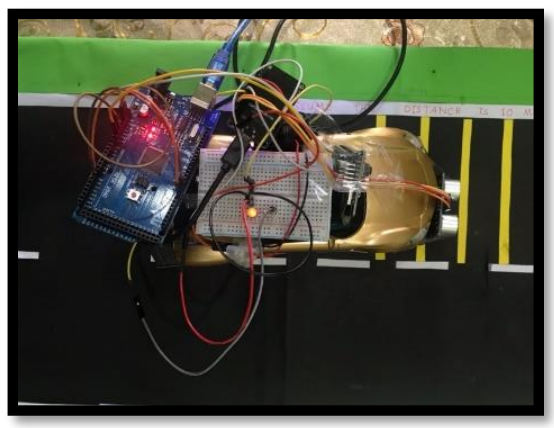

Figure 8: Ultrasonic sensor testing 


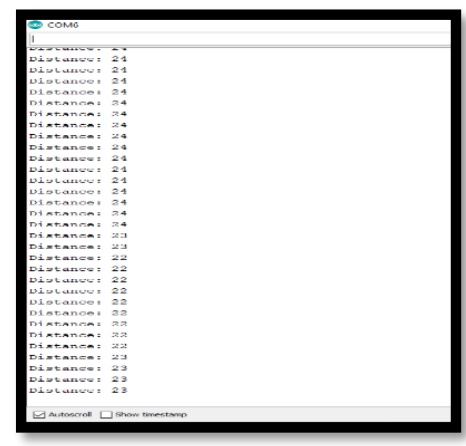

Figure 9: Serial monitor shows the distance between the ultrasonic sensor and speed bump

\section{Full Circuit Testing}

Full circuit testing was performed to ensure that all functions perform satisfactorily. All components were accumulated in the finalized circuitry and re-tested to ensure that all sensors and device modules were running perfectly. To ensure that the user was satisfied with the prototype, a set of test cases was performed, as detailed in Table 1 below:

Table 1: A test case for the Ultrasonic sensor

\begin{tabular}{|c|c|c|c|}
\hline Test Case Name & \multicolumn{3}{|l|}{ Ultrasonic sensor } \\
\hline $\begin{array}{l}\text { Test Case } \\
\text { Description }\end{array}$ & \multicolumn{3}{|c|}{$\begin{array}{l}\text { 1. To check the ultrasonic sensor can detect the existence of a speed bump on } \\
\text { the road. } \\
\text { 2. To ensure the ultrasonic sensor will detect a speed bump if the distance } \\
\text { between vehicle and speed bump is less than } 10 \mathrm{~m} \text {. } \\
\text { 3. To ensure that the ultrasonic sensor will notify the user if the vehicle } \\
\text { approaching the speed bump is in the range of less than } 10 \mathrm{~m} \text { through sound } \\
\text { from the buzzer and Blynk application and also red light from the LED. }\end{array}$} \\
\hline Pre- Condition & \multicolumn{3}{|c|}{$\begin{array}{l}\text { 1. The ultrasonic is connected perfectly to the Arduino Nodemcu EP32 by } \\
\text { using a jumper wire. }\end{array}$} \\
\hline Step & Test Description & Expected Result & Result \\
\hline 1. & $\begin{array}{l}\text { An ultrasonic pin will be connected to } \\
\text { the Nodemcu ESP32 board pin by using } \\
\text { a jumper wire. }\end{array}$ & $\begin{array}{l}\text { The Ultrasonic sensor } \\
\text { will show a blinking } \\
\text { red light. }\end{array}$ & Pass \\
\hline 2. & $\begin{array}{l}\text { Put a resistance in front of the ultrasonic } \\
\text { sensor. }\end{array}$ & $\begin{array}{l}\text { The Ultrasonic sensor } \\
\text { will give a sound from } \\
\text { the buzzer and Blynk } \\
\text { applications if the } \\
\text { resistance is below } \\
10 \mathrm{~m} \text {. }\end{array}$ & Pass \\
\hline
\end{tabular}


Table 2: A test case for the Camera Module

\begin{tabular}{|c|c|c|c|}
\hline Test Case Name & \multicolumn{3}{|l|}{ Camera Module } \\
\hline $\begin{array}{l}\text { Test Case } \\
\text { Description }\end{array}$ & \multicolumn{3}{|c|}{$\begin{array}{l}\text { 1. To test that the camera module can display a view in front of it. } \\
\text { 2. To ensure that the camera module will give a display visionary to the road } \\
\text { user. }\end{array}$} \\
\hline Pre- Condition & \multicolumn{3}{|c|}{$\begin{array}{l}\text { 1. The camera module will be connected properly to the Arduino Mega } 2560 \\
\text { board using a jumper wire. }\end{array}$} \\
\hline Step & Test Description & Expected Result & Result \\
\hline 1. & $\begin{array}{l}\text { The camera module pin will be } \\
\text { connected to the Arduino Mega } 2560 \\
\text { board pin by using a jumper wire. }\end{array}$ & $\begin{array}{l}\text { The camera module } \\
\text { will activate. }\end{array}$ & Pass \\
\hline 2. & $\begin{array}{l}\text { Place an object in front of the camera } \\
\text { module }\end{array}$ & $\begin{array}{l}\text { The camera module } \\
\text { will show an object } \\
\text { image in front of } \\
\text { the camera. }\end{array}$ & Pass \\
\hline
\end{tabular}

\section{CONCLUSION}

The Integrated Speed Bump Detector is a detector that can help road users to detect speed bumps before approaching them. By using this detector, road users can detect speed bumps earlier through sound coming from the buzzer and blinking red light from the LED; this assists them to drive safely to their destination. This proposed prototype can be further enhanced in future designs. For example, an LCD screen can be utilised to visually project the distance between the vehicle and the speed bump. A high-resolution camera can also be considered to provide a clearer view of the road ahead, as well as any object detection sensors to detect any obstacles ahead of the vehicle. 


\section{REFERENCES}

ACPLM (2019). 5 Things You Didn't Know About Speed Bumps. https://www.acplm.net/5-things-didnt-knowspeed-bumps/

Attia, H. A., Ismail, S., Alia, H. Y. (2016, December 6-8). Vehicle safety distance alarming system [Paper presentation]. 2016 5th International Conference on Electronic Devices, Systems and Applications
(ICEDSA),
Ras
Al Khaimah,
United
Arab
Emirates.

https://www.researchgate.net/publication/312561167_Vehicle_safety_distance_alarming_syst

Khalil, U., Nasir, A., Khan, S. M., Javid, T., Raza, S. A., Siddiqui, A. (2018, November 1-2). Automatic Road Accident Detection Using Ultrasonic Sensor [Paper presentation]. 2018 IEEE 21st International MultiTopic Conference (INMIC), Karachi, Pakistan. https://www.researchgate.net/publication/330030161_Automatic_Road_Accident_Detection_Using_Ultr asonic_Sensor

Muhaiyiddin, F., Sanudin, R., Wahab, M. H. A., Johari, A. (2009, April 3-5). Development of Digital Vehicle Distance Monitoring System [Paper presentation]. 2009 International Conference on Future Computer and Communication, Kuala Lumpur, Malaysia. https://www.researchgate.net/publication/261057061_Development_of_Digital_Vehicle_Distance_Monit oring_System

Patel, M. Gundaliya, P. J. (2017). A study on Speed Breakers. International Journal of Advance Engineering and Research Development, 4(3), 368-372.

Rapid Application Development (RAD): Changing How Developers Work. (2021, September 5). Low-Code. https://kissflow.com/low-code/rad/rapid-application-development/

Sueb, S. (2013, April 17-19). The Development Of Technology For Human Civilization. 3rd Annual Basic Science International Conference, Universitas Brawijaya Malang, Indonesia. https://www.researchgate.net/publication/282660350_The Development_Of_Technology_For_Human_Ci vilization

Walter, M. (1997). Rapid Application Development. https://web.cs.dal.ca/ jamie/teach/WaltManer/RAD.htm\#8

World Health Organization (2018). Road traffic injuries. https://www.who.int/news-room/factsheets/detail/road-traffic-injuries 